\title{
An update on the activities of the College Research Unit
}

\author{
Paul Lelliott
}

The College Research Unit (CRU) has expanded rapidly since the Psychiatric Bulletin published a description of its establishment and early audit work (Lelliott, 1992).

The most obvious sign of this expansion has been the need for the unit to spill over into larger premises. Fortunately these are within three minutes walk of the College which, together with electronic and telephone links, means that the CRU remains just as closely involved with the other work of the College.

So far, the CRU has attracted nearly $£ 1.5 \mathrm{~m}$ in grants to supplement the core funds donated by College members. The unit now employs five full-time research workers, a unit administrator (Rachel Bartlett-Larsen) and a full-time unit secretary as well as its Director (John Wing) and Deputy Director (Paul Lelliott). In addition to these core workers, the CRU administers the budgets of, or closely supports, other projects whose six workers are based elsewhere.

The recent work of the CRU has advanced all of the unit's four major aims, which are to provide:

(a) systemic and accurate data on which the College can construct agreed clinical guidelines

(b) information and suggestions for improving the structure and function of mental health services

(c) advice on, and help to construct, mental health information systems

(d) the basis for an advisory centre for clinical audit.

The effectiveness of this work has been greatly enhanced by a reorganisation of audit and mental health informatics within the College. This restructuring followed recommendations of a Mental Health Information Systems Working Group (MHISWG, 1992) set up by the Research Committee and serviced by the CRU. Council has now established a Special Committee, reporting directly to the Executive and Finance Committee, in order to deal promptly with the many queries, projects and educational and policy implications arising in these rapidly developing and overlapping fields. It will be chaired by the Registrar, Professor Chris Thompson, and the Secretary will be the Deputy Director of the CRU, Dr Paul Lelliott. A grant from central audit funds supports the establishment of a College Audit and Information Technology Office (CAITO), and the appointment of an officer (Miss Suzanna Goodwyn) to service the Special Committee. The functions of both will be more fully described in a future issue of the Bulletin.

\section{Clinical guidelines and the structure of services}

Members of the CRU have gained valuable experience of multidisciplinary audit procedures and various projects are at various stages of the audit cycle.

Audit of administration of electro-convulstue therapy. The College has acted decisively in response to the findings of the CRUcommissioned survey of ECT practice in two English regions (Pippard, 1992). The next step for the CRU will be to repeat the survey after an appropriate interval to discover whether the 'audit cycle' has been successfully completed and practice improved.

Gutdelines on schizophrenia. CAITO and the CRU has recently coordinated the production, for the Clinical Standards Advisory Group, of draft guidelines on the care of people with schizophrenia.

Audit of acute admissions. The survey component of this audit of consecutive admissions to acute psychiatric beds in two inner London districts (Hammersmith and Fulham and Southwark) has now been completed. The study has provided information about the characteristics and clinical and social problems of people admitted, the particular reasons for admission and whether admission could have been prevented if other services had been available. Particular attention has been given to the interaction between district characteristics, admission under the Mental Health Act and ethnicity. The results will be published soon. 
Audit of 'new long-stay' patients. In the first of what will be a series of multi-centre audits, standard returns were collected from 59 districts and health boards, providing information about 905 'new long-stay' (NLS) patients, aged under 65 , who had been in hospital between six months and three years. This substantial group occupies a central place in determining the structure of local services.

Key findings were as follows

(a) Despite pressures to discharge early and manage patients in the community, there were over 3,000 NLS patients in British psychiatric hospitals on the census day (in March 1992).

(b) A quarter of NLS patients were housed on acute wards, unsuitable for such a lengthy stay.

(c) Despite many patients being potentially violent, or liable to self-neglect, two-thirds could have been discharged; for many this was prevented because suitable alternative community-based accommodation was not available or was already full.

Draft guidelines on practice and service planning to address the NLS problem have been drafted for CAITO to take forward to the Special Committee.

Survey of long-term restdential care. A brief audit survey, focusing on long-term non-hospital residential services for chronically mentally ill people in Cambridge, has been commissioned and completed. It supplements the new long-stay project. Cambridge was chosen because the quality and scope of the housing provided there would enable a description of a model that clinicians and managers in other districts can compare with their own and that the College can also consider when drawing up guidelines.

Use of extsting health statistics for audit. Dr Gyles Glover has worked with psychiatrists in Huddersfield to pllot the establishment of an audit database using routinely collected clinical and administrative data.

Recommendations for guidelines and standards will be drawn from each of these projects. How these will be used to influence practice is a question of interest to the CRU. One possible mechanism might be for the incorporation of guidelines or standards into the service contracts between purchasers and providers.

\section{Mental health informatics}

Members of the College engaged in local audit, and in clinical and administrative management, have voiced concern about the multiplicity and variety of prototype mental health information systems and the inadequacy of existing 'minimum data sets' being developed for the routine collection and processing of clinical information. As part of its audit commitment, as well as for wider public health and administrative purposes, the College needs to provide, sooner rather than later, guidelines on the content, structure, and technical specifications of such systems. Further action is being taken as follows.

Minimum clinical data set. This was drafted and included as an appendix to the MHISWG Report. It is intended for wide discussion by mental health professionals of all disciplines and will be piloted as part of the liaison activities described below.

Content and function of mental health information systems. The CRU made a preliminary survey of functioning clinical information systems that met minimum criteria and are already working in health districts. This has now been published (Lelliott et al, 1993), as has a survey of coding systems (Shanks, 1992).

Liaison group. The Working Party membership overlapped with that of a liaison group of people concerned with the provision of good quality mental health service information. These include promising new information systems, the Casemix Office, the National Centre for Coding and Classification, the Community Information Systems Project, Resource Management sites, and members of information strategy projects in the Department of Health. Close working links have developed between the members of the group (Anthony et al, 1993; Rigby \& Robins, 1993; Wing, 1993).

Health of the Nation Outcome Scales (HONOS). The first target for improving mental health, identified in Health of the Nation (Department of Health, 1992) is "to improve significantly the health and social functioning of mentally ill people". The CRU has been commissioned to undertake the construction of a set of brief scales for measuring outcomes that can help to assess progress towards this target. Piloting is in progress and full trials will begin in early 1994.

FACE development. FACE (Functional Analysis of Care Environments) is a developing computerised patient-based information system intended to record and measure the problems presented by patients, the care they are prescribed, the environments in which care takes place, the costs involved, and quality of achievement (Clifford, 1992). One part of this development, to use FACE information to measure outcomes, is 
funded through the College and is of obvious relevance for comparison with the HONOS project.

Schedules for Clinical Assessment in Neuropsychiatry (SCAN). SCAN, a standardised psychiatric interview and associated instruments, is based on a comprehensive glossary of differential definitions of symptoms and signs, to which can be applied computerised rules for ICD-10 and DSMIII- $R$ diagnoses, is a development from the earlier PSE-ID-CATEGO system, now sponsored by WHO and ADAMHA (Wing, 1992; Wing, Sartorius \& Ustün, 1993). A computer-assisted version is available (Glover, 1992). The latest development is the arrival of DSM-IV, which will be incorporated.

Clinical Terms Project (The Read Codes). An essential first step towards building a more clintcally useful health information system is to establish an agreed nomenclature, or thesaurus, of terms at present used in NHS clinical records, each one with a unique identifier (the Read Code). The method of developing codes and the role of the CRU have already been described (Wing, 1993).

Mental health needs of a defined population. This new NHS Research and Development funded project started in July 1993. There are two related studies, designed to provide and test simple methods of determining needs for high-cost restdential mental health care in defined populations. The first is focused on directly measured needs of those in all forms of accommodation for the mentally ill in eight districts. The results of this study will allow a critical test of the statistical indices developed (and tested more widely but more generally) in the second study.

\section{The future}

Many of the individual and collaborative projects described above are close to completion and will provide a substantial part of the input to CAITO and the Special Committee during the first year of their work.

Centre for the Economics of Mental Health. The CRU is collaborating with this newly-established
Centre at the Institute of Psychiatry (Director, Professor Martin Knapp) which will provide an extra dimension for relevant audit studies during the coming years. The first collaboration will be to add a costing element to the $R \& D$ project described above.

Audit of delays in obtaining Mental Health Review Trlbunals. This grant application, to audit this area of public concern, is still being considered by the DoH. If successful, the work will be conducted in collaboration with Dr Simon Wessely.

\section{References}

ANThoNy, P., ElPhick, M. \& LeLuott, P. (1993) Casemix in psychiatry. Psychiatric Bulletin, 17, 8-9.

CLIFFORD, P. (1992) FACE: Functional Analysis of Care Environments. Quality Development Unit, Abbey House. 4 Abbey Orchard Street, London SW1P 2JJ.

DEPARTMENT OF HEALTH (1992) The Health of the Nation: a strategy for health in England. HMSO: London.

GLOVER, G.R. (1992) CAPSE-10. Computer assisted PSE10. Geneva: WHO.

LeLuotr. P. (1992) The College Research Unit and its clinical audit programme. Psychiatric Bulletin, 16, 313-315.

-. Flannigan, C. \& Shanks, S. (1993) A Revtew of Seven Mental Health Information Systems. A functional perspectwe. Research Unit Publication No 1. London: Royal College of Psychiatrists.

MENTAL HEALTH INFORMATION SYSTEMS WORKANG GROUP (1992) Report to the College Research Committee. Avallable from the College Research Unit.

PIPPARD, J. (1992) Audit of electroconvulsive treatment in two NHS regions. British Journal of Psychiatry. 160. 621-637.

RigbY, M. \& RobINs, S. (1993) Resource management in mental health. Psychiatric Bullettn (in press).

Shanks, S. (1992) Coding and Mental Health Information Systems: a review of current approaches. Avallable from the College Research Unit.

WNG. J.K. (Chief Editor) (1992) SCAN. Schedules for Clinical Assessment in Neuropsychiatry. Manual, Glossary and Recording Booklets. Geneva: World Health Organization.

- (1993) Read codes for the mental health professions. The Clinical Terms Project. Psychiatric Bulletin, 17, 195-196. -, SARTORIUS, N. \& ÜSTÜN, T.B. (1993) Diagnosis and Clintcal Measurement in Psychiatry. A reference manual for the SCAN system. Cambridge: Cambridge University Press (in press).

Paul Lelliott, Deputy Director, Research Unit, Royal College of Psychiatrists, 11 Grosvenor Crescent, London SWIX 7EE. 